\title{
EDUCATIONAL RESEARCH AND EVIDENCE-BASED PRACTICE
}

Martyn Hammersley (ed.)

London: Sage, The Open University, 2007, 295p.

Trata-se de obra coletiva organizada por Martyn Hammersley', a partir de uma polêmica provocada pela conferência de David Hargreaves na abertura da reunião anual da Teacher Training Agency, em 1996. A conferência desencadeou uma série de reações, em forma de artigos, sobretudo uma vasta discussão em torno da questão da pesquisa em educação, em sua função precípua de construção de conhecimentos (poursuing knowledge for its own sake), bem como em suas relações com a política e a prática em educação. Ela também chamou atenção sobre a ideia um tanto perturbadora

I. Professor de Educação e Pesquisa Social, da Faculdade de Educação e Estudos da Linguagem, na OpenUniversity (general-enquiries@open.ac.uk). 
das "evidências" e seu papel, na produção de conhecimentos pela pesquisa (evidence-based research), que passou a ocupar grande espaço nas discussões acadêmicas. Toda a década viu essa ideia aparecer nas páginas de livros e artigos, mas também nas proposições de reforma feitas pelos governantes. Em paralelo, foram levantadas velhas querelas em torno do positivismo, ou melhor, da pesquisa baseada sobre dados quantitativos e de experimentação, em confronto àquelas mais orientadas para análises qualitativas, segundo suas diferentes denominações. É justamente esse panorama que Hammersley procurou apresentar em seu livro, no que foi bem-sucedido. Ele organizou uma seleção de textos muito bem escolhidos, que ilustram o desencadeamento da polêmica nos anos de 1996 e seguintes, mas também reuniu trabalhos de datas mais ou menos recentes, tratando de aspectos ligados à polêmica, sob o ponto de vista teórico, ou em suas aplicações à prática. $\bigcirc$ livro está dividido em duas partes, a primeira parte, consagrada ao debate sobre as questões levantadas pela conferência, a segunda, centrada sobre a natureza da pesquisa em educação, a partir de discussões sobre exemplos representativos das características e dos problemas próprios dessa investigação.

Não seria possível, nos limites desta resenha, cobrir a variedade e a riqueza das discussões levantadas pelos 18 textos reunidos. Vou me limitar à indicação dos que discutem pontos de interesse geral, lembrando que os outros merecem também a atenção dos leitores. É preciso assinalar, logo, o sucesso do organizador em seu esforço para localizar, recolher, selecionar e apresentar, em um só volume, uma série de textos, publicados em periódicos de vários países, que oferecem ao leitor a possibilidade de entrar em contato direto com diferentes posições e perspectivas sobre a questão central. Sua leitura será muito produtiva para professores e estudantes uni- versitários e, obrigatória, para pesquisadores.

A primeira parte se inicia pelo texto da conferência de Hargreaves de 1996. Como professor da Faculdade de Educação da Universidade de Cambridge, na época, ele fala do interior da comunidade acadêmica, o que tornou bastante difícil para ela receber as críticas contidas em seu discurso, que não era, entretanto, dirigido somente aos membros dessa comunidade, mas a um público bem mais amplo. Suas críticas tiveram grande eco, com repercussões sobre as políticas de reformas visíveis até nossos dias. A publicação do conjunto de textos reunidos por Hammersley, a partir da famosa conferência, permanece, portanto, inteiramente atual e pode marcar uma etapa na evolução da pesquisa em educação, não apenas no Reino Unido.

A grande desaprovação de Hargreaves dirigida à pesquisa em educação se deve a sua fraca contribuição para um ensino mais eficaz, assim como para proposições de reformas destinadas a enfrentar problemas há muito conhecidos pelos pesquisadores, que continuam afligindo alunos e professores em suas escolas. Além disso, ele menciona com desapontamento as grandes somas de recursos destinados ao orçamento da pesquisa em educação, sem resultados correspondentes, sob o ponto de vista do custo/benefício. A partir de uma comparação com o que se passa na medicina, o autor levanta a questão da pesquisa baseada sobre evidências, que trazem um grau de segurança bem elevado às medidas tomadas pelos médicos em relação a seus pacientes, diferentemente do que se passa entre os professores e seus alunos. Ele assinala, também, como positiva, a proximidade entre os pesquisadores dos laboratórios e os que praticam a medicina, os médicos das clínicas, que se mostram, em geral, mais bem informados sobre resultados de pesquisas do que os docentes em seu trabalho nas escolas. Em consequência, 
há na medicina uma interação fértil entre os profissionais dos dois polos, em termos de pesquisa. Nota-se, nas críticas de Hargreaves, um verdadeiro descontentamento sobre a fraca acumulação de conhecimentos por parte da pesquisa em educação, para servir à prática e às políticas da educação. Ele está convencido de que, voltando-se para um trabalho guiado por métodos que procurem resultados seguros, baseados em evidências, essa pesquisa irá encontrar o bom caminho.

Em seguida, na primeira parte do livro, se irá desenrolar uma pequena batalha acadêmica entre os dois experimentados pesquisadores: Hammersley, o organizador da obra, com um artigo publicado logo depois da apresentação de Hargreaves, discute seus pontos principais, seguido de uma resposta deste, e ainda de um segundo artigo de Hammersley. Esse conjunto de quatro textos oferece aos leitores a excelente oportunidade de conhecer, em detalhes, os elementos introduzidos na disputa por cada um dos dois participantes, compondo assim um rico quadro sobre a questão central, a situação da pesquisa em educação na época, e ainda hoje sob vários aspectos. Os artigos de Hammersley discutem cada argumento apresentado por Hargreaves, concordando com ele sobre a importância de tornar a pesquisa em educação mais próxima de um tratamento mais científico, mas ressaltando a dificuldade de estabelecer critérios que possam confirmar claramente evidências no campo da educação. Diferentemente de Hargreaves, Hammersley pondera que os traços, em geral, reconhecidos como próprios do trabalho científico mais rigoroso, como as medidas precisas dos fenômenos e o tratamento experimental das causas que expliquem as relações entre eles, não têm uma aplicação fácil no domínio da educação. Um outro aspecto sobre o qual ele assinala seu desacordo se refere à importância atribuída por Hargreaves às relações entre a pesquisa e a prática, ou antes, entre os pesquisadores e os docentes. Segundo Hammersley, uma preocupação excessiva com uma orientação mais prática e ao mesmo tempo mais científica, pode causar mais problemas do que ajudar o desenvolvimento da pesquisa em educação. A comparação com a medicina fica também bem mais nuançada em sua visão, que não reconhece como seu colega o peso das evidências como tão significativo, mas aceita algumas lições vindas das comparações. As respostas de Hammersley provocam discussões ainda mais detalhadas de seu opositor, o que torna o debate ao mesmo tempo muito informativo e interessante.

Ainda na primeira parte do livro, um longo artigo de John Elliott, pesquisador sênior da Universidade de East Anglia, autoridade internacional sobre questões ligadas à pesquisaação, discute de modo especial a perspectiva de Hargreaves sobre esse tipo de pesquisa. Basicamente, Elliott ressalta as limitações de uma visão sobre a pesquisa em educação limitada entre o modelo do enlightenment e o da engineering. Temos necessidade, segundo ele, de um modelo que coloque os julgamentos dos professores no centro do processo de pesquisa. Muito mais que de standards fixados pelas proposições de reformas governamentais, os docentes têm necessidade de um apoio teórico, por certo, fundado sobre pesquisas capazes de alcançar a complexidade dos fenômenos da educação, como é o caso da pesquisa-ação e de outros tipos de pesquisa do gênero qualitativo. $\bigcirc$ apelo à "prática reflexiva'" não basta, segundo Elliott, para preencher as condições necessárias à atividade de pesquisa. Evocando Lawrence Stenhouse, pesquisador que inspirou o trabalho do grupo de East Anglia desde os anos de 1970, Elliott analisa as diferenças entre os dois autores, Hargreaves e Stenhouse, sobre a ideia de professor-pesquisador, assimilada por 
Hargreaves àquela do reflective practitioner. Trata-se, talvez, de uma questão de perspectivas: Hargreaves se preocupa em definir "a pesquisa como uma base para a prática, enquanto Stenhouse define a prática como uma base para a pesquisa" (p.86). Elliott conclui seu artigo insistindo na falta de uma teoria sobre a natureza da prática educativa, para informar as discussões sobre o currículo e a educação em geral. Essa teoria teria, segundo ele, implicações muito benéficas sobre a pesquisa em educação.

Logo após o longo artigo de Elliott se encontra uma curta reação de Ann Oakley, sobre a falta de clareza do conceito de positivismo empregado por Elliott e sua resistência a aceitar a importância da explicitação dos resultados de pesquisa, sobretudo no interesse dos alunos e seus pais. Em seguida, a mesma autora, em artigo mais extenso, desenvolve interessante discussão a propósito das dificuldades de obtenção de evidências na pesquisa das ciências sociais, para servir de base às políticas públicas da educação. Mesmo a palavra "evidência" não é, por vezes, claramente definida, e expressões como "informação baseada sobre evidências" são empregadas sem melhores explicações. As sínteses de pesquisas destinadas a reunir resultados, ou evidências, para informar as decisões políticas ou práticas, sofrem sérias limitações, muito bem analisadas por Oakley. Ela apresenta vários exemplos de tentativas que ela considera muito distantes da noção de síntese de pesquisa, como uma atividade orientada por critérios de inclusão e exclusão bem definidos, de busca sistemática e de métodos específicos para a avaliação da qualidade dos diferentes estudos analisados (p.96).

A primeira parte do livro apresenta ainda um vibrante texto de Stephen Ball, confrontando intelectuais e tecnicistas, em um mundo acadêmico capturado por uma orientação para reestruturações financeiras combinada com um pacto de Fausto. Como resultado, as perspectivas de pesquisa, bem como seu financiamento, são cada vez mais submissas à agenda política dos governantes. Somente o apoio da teoria pode libertar o pesquisador dos ingênuos a priori ontológicos e epistemológicos, bem como das pré-concepções não examinadas e não refletidas. "A teoria é um veículo para pensar diferentemente" (p. I 16).

$\bigcirc$ artigo de Alex Moore, que fecha a primeira parte, joga com as duas apresentações gráficas do conceito de reflexivo em inglês (reflective e reflexive), assinalando que "as competências e os discursos do reflective practitioner eram úteis, mas foi o discurso reflexivo que ativou plenamente essa utilidade" (p. I35).

A segunda parte do livro, consagrada à natureza da pesquisa educacional, apresenta exemplos de afirmação e de discussão dessa pesquisa, como um domínio próprio de investigação, com sua especificidade e seus problemas ao longo de sua história. "Já é tempo para a pesquisa em educação afirmar que sua época chegou", para deixar a casa dos pais (psicologia, sociologia) e se afirmar sobre seu próprio solo, diz M. Bassey, no primeiro artigo (p. 132).

Nathaniel Gage, com dois textos, é o único autor presente na seleção organizada por Hammersley, vindo de um país fora do Reino Unido, ainda que sua produção científica seja em língua inglesa. É um pesquisador sênior americano, muito conhecido nos Estados Unidos por suas numerosas obras, responsável por uma das edições do importante compêndio publicado pela American Educational Research Association - Aera -, Handbook of research on teaching, uma espécie de balanço da pesquisa sobre o ensino, que aparece em períodos não regulares, marcando o que de importante aconteceu nesse domínio. Ele publicou, no fim dos anos de 1970, um livro cujo título já é revelador de sua intenção bastante ousada: The scientific basis of the art of teaching (1978). 0 
primeiro texto de Gage é uma reprodução de seu famoso artigo "The paradigm wars and their aftermath", publicado no Educational Researcher, v. I8, 1989, da Aera. O título já anuncia a importância do tema, que atraiu a atenção de muitos leitores, cuja leitura continua muito interessante. Ele faz um exercício de futurologia, projetando o pensamento até o ano de 2009. Sua análise consiste em imaginar como se passam as coisas depois do desencadeamento da guerra dos paradigmas, começando logo antes de 1989, até 2009. Com bastante humor e certa dose de ironia, ele visualiza três cenários possíveis. O primeiro nos anos de 1990, quando os antinaturalistas, os interpretivistas e os teóricos críticos triunfaram sobre os objetivistas, quantitativistas. As pesquisas do tipo experimental ou correlacional quase desapareceram, deixando lugar aos estudos baseados sobre a observação e a interpretação. Em um segundo cenário, a partir de uma reação por parte de pesquisadores objetivistas-quantitativos, que se despertaram de seu torpor, e também pelo próprio desenvolvimento das pesquisas qualitativas, houve uma evolução geral, os diferentes objetos de estudo do campo da educação receberam um tratamento metodológico compatível com sua especificidade e o componente de oposição entre os paradigmas foi considerado inválido. Mas, no terceiro cenário, já dentro do século $X X I$, as coisas se voltaram para o clima competitivo reinante antes de 1989, na mesma condição de guerra paradigmática, segundo Gage. Ele se pergunta quanto tempo ela ainda vai durar e qual será o destino da pesquisa em educação. São questões que não se pode responder, mesmo em 2009, ele diz! Qual será a versão verdadeira? Para responder ele volta a 1989 e propõe: "a resposta do futuro se encontra conosco, com vocês. O que vocês fizerem nos anos que virão vai determinar se as guerras continuam" (p. 164).

Gage é também autor do último texto do livro, tratando ainda de um tema provocativo: a obviedade aparente de resultados das pesquisas em educação. De novo, ele discute seu tema a partir de vários exemplos extraídos de pesquisas muito conhecidas. Ele consegue demonstrar claramente a importância desses estudos, que vão além das aparências, nas quais os resultados parecem óbvios, mas na realidade mostram por vezes até pontos opostos, quando a pesquisa pode ser prosseguida. Há sempre uma série de fatores que só podem ser revelados a partir do esforço da pesquisa.

Stephen Kemmis, em um texto curto, apresenta uma bela defesa da pesquisa-ação, não como a melhor forma de pesquisa, e menos ainda a única, capaz de fornecer resultados importantes para a transformação de políticas da educação. $\bigcirc$ autor considera, entretanto, que ela tem sido infrautilizada no caminho para uma sociedade democrática, na qual a participação dos profissionais da educação é fundamental.

Janet W. Schofield trata de um assunto muito importante, mas pouco estudado: a generalização em pesquisas qualitativas. Em seu artigo ela apresenta uma sugestão que merece leitura detalhada e pode ajudar os pesquisadores no difícil problema da escolha da amostra. Essa escolha deve se orientar pelo interesse do estudo sobre "o que é, o que pode ser ou o que poderia ser" o objeto estudado (p. 195).

Dois textos devem ainda ser mencionados, pois representam um esforço de informação e formação. Primeiro a apresentação de um estudo de caso sobre um programa de ensino industrial para alunos com dificuldades de aprendizagem (slow learners), em um texto de Atkinson, Shone e Rees. Em seguida, um texto de Hammersley apresenta uma análise detalhada sobre esse estudo de caso, chamando atenção sobre seus pontos mais frágeis no aspecto metodológico, de modo especial no que se refere às evidências e suas interpreta- 
ções pelos autores. Em um livro que discute o papel das evidências na pesquisa e na prática da educação, os dois textos parecem muito bem situados.
Professora titular do Departamento de Educação da Pontifícia Universidade Católica do Rio de Janeiro menga@puc-rio.br

Menga Lüdke 